\title{
A organização do ensino fundamental em ciclos: algumas questões
}

\author{
Ocimar Munhoz Alavarse
}

Universidade de São Paulo, Faculdade de Educação

\section{Introdução}

Neste trabalho, problematiza-se a adoção dos ciclos como forma de organização do ensino fundamental enquanto política pública de educação para a democratização da escola. Os ciclos, entre outros aspectos, estabelecem, pelo menos potencialmente, uma polarização com a escola seriada e, apesar das diferenças entre várias iniciativas, sua lógica dominante é a tentativa de superar o fracasso escolar, expresso particularmente pelas altas taxas de reprovação, identificando-se na seriação um fator que o favorece.

Como nota histórica, é a partir do início dos anos de 1980, com o chamado ciclo básico abarcando as duas séries iniciais, que a temática ganha proeminência nos debates educacionais brasileiros, mesmo que antes desse período tenham se registrado iniciativas com algumas semelhanças, como em 1920, a Reforma Sampaio Dória no ensino paulista. Com a Lei de Diretrizes e Bases da Educação Nacional (LDB), de dezembro de 1996, notadamente pela incorporação da possibilidade dos ciclos, assiste-se a um sensível acréscimo de experiências em prol de sua adoção. Para um panorama histórico desse processo pode-se consultar Mainardes (2001).
Em algumas iniciativas de redes públicas de ensino, os ciclos caracterizaram-se mais por atenuar os critérios de avaliação existentes na seriação, mediante a introdução da progressão continuada entre algumas séries - que foram agrupadas sob a denominação de ciclos - e mantida, na maioria dos casos, a possibilidade de reprovação por desempenho ao final de cada ciclo. Em outras situações, as medidas foram mais intensas, com mudanças curriculares, incluindo avaliação, rearranjo dos tempos escolares e alterações no trabalho docente.

A adoção dos ciclos produziu uma acirrada polêmica, com destaque nos meios de comunicação e envolvimento de autoridades educacionais, com manifesta resistência de professores, que associam ciclos a queda da qualidade do ensino. No ambiente acadêmico, embora também se possa constatar opositores, os ciclos parecem gozar de maior adesão, havendo restrições quanto à maneira pela qual foram implantados, e já se identifica produção intelectual sobre a temática, como em Mainardes (2004) e Sousa e Barretto (2004).

Os ciclos podem ser problematizados pelo alcance que ensejariam, em várias dimensões, no sentido da democratização da escola como garantia de aten- 
dimento da histórica reivindicação de pleno acesso por parte de amplas camadas sociais. Evidentemente, não se trata de desconsiderar outros fatores que condicionam a democratização da escola, abarcando seu financiamento, a formação de professores, as condições materiais das escolas etc. No escopo deste artigo, trata-se de enfocar o potencial de um aspecto - a organização escolar - que não deveria ser negligenciado.

\section{Os ciclos e a democratização da escola}

Pode-se delimitar, como ponto de partida para a compreensão do alcance dos ciclos, o caráter compulsório do ensino fundamental. Embora historicamente seja possível identificar demandas populares pelo direito à escolarização, isso não significa a existência de "convivência pacífica" dos filhos de trabalhadores obrigados a frequentar a escola, particularmente daqueles mais depauperados, frente às exigências dos procedimentos intraescolares. Ao contrário, o que se nota é um processo histórico no qual se evidencia uma acentuada seletividade da escola, cuja conclusão parece inatingível para muitas crianças. Além disso, a genérica aspiração popular por escola não produz, empiricamente, a adesão de todas as crianças que o Estado convoca a partir dos seis anos de idade, derivando daí uma tensão entre direito e dever que Cury (2002) assinalou.

Como consequência do entendimento do sentido político da obrigatoriedade, por conseguinte, não se pode analisar essa etapa da educação básica como se milhões de alunos aí se encontrassem por uma opção própria absoluta, significando que não se pode exigir dos alunos o interesse em relação à escola - como um pré-requisito - nem mesmo “prontidões” cognitivas. Essa imposição do ensino fundamental transforma em tarefa da escola promover tanto o interesse do aluno por ela quanto a prontidão dos conhecimentos.

A democracia em relação à escola obrigatória não pode ser tomada como a liberdade de escolha dos indivíduos, ainda mais se sabemos das implicações sociais, ulteriores, dos resultados escolares e, sobretudo, conhecendo as altas e persistentes taxas de reprovação e abandono escolares em todas as séries do ensino fundamental. Essa tarefa se adensa se considerarmos a questão democrática, como ponderou Canfora (2007, p. 326-327):

\footnotetext{
O facto é que precisamente por não ser uma forma, por não ser um tipo de constituição, é que a democracia pode existir ou existir apenas em parte ou não existir de todo, ou então voltar a afirmar-se no âmbito das mais diferentes formas político-constitucionais.
}

\begin{abstract}
Aquela que, por fim - aliás, no estado actual das coisas -, levou a melhor foi a “liberdade”. A liberdade está a derrotar a democracia. A liberdade, entenda-se, não de todos, mas daqueles que, na corrida, são mais “fortes” (nações, regiões, indivíduos): a liberdade reivindicada por Benjamin Constant com o significativo apólogo da "riqueza" que é "mais forte do que os governos".
\end{abstract}

É preciso atentar que admitir a obrigatoriedade escolar pode se fazer acompanhado do argumento que responsabiliza o aluno, em última instância, pelos resultados escolares, que têm consequências decisivas, ao qual não teria sido negada a possibilidade de acesso à escola, de onde sairá e, por mérito, disputará os melhores lugares na hierarquia social. Historicamente, no ideário liberal, essa posição, ao combater os privilégios das condições de nascimento e alongar a obrigatoriedade, com o consequente aumento das oportunidades, foi empregada no intuito de aumentar a coesão social em torno de um contrato social pelo qual perdedores e ganhadores devem reconhecer a justeza das regras e dos resultados. Nesses termos, a obrigatoriedade se restringiria à igualdade de oportunidades.

Assim, a democratização da escola, numa perspectiva que ultrapasse esse ideário, exige observar a obrigatoriedade em todas as suas implicações para evitar que, mesmo quando da ampliação de sua duração, seja transformada em mecanismo de produção de uma elite. O compromisso com a igualdade de oportunidades não acarreta, nem lógica nem politicamente, compromisso com igualdade de resultados, que deve 
ser o grande objetivo de uma escola que se impõe como necessária socialmente. A igualdade de resultados, compreendida como uma tarefa democrática, significa a possibilidade de que todas as crianças ascendam a patamares considerados indispensáveis para a vida da nação; trata-se radicalizar a democracia. Crahay (2002), aliás, evidencia que a consolidação da escola tem sido pródiga em se afastar da "democratização" dos resultados e, às vezes, sem garantir aquela das oportunidades.

Nesse cenário, pode-se adendar, a obrigatoriedade escolar tem como variante o inatismo, que confere a certos indivíduos capacidades intelectuais apriorísticas e superiores, cuja defesa da escola seria para identificar tais indivíduos e dar-lhes condições de potencializar essas capacidades herdadas. Gould (1999), ao se contrapor a tal vertente, explicita como floresceu, sobretudo nos Estados Unidos da América, não só uma fundamentação biologista como também as práticas psicométricas, destacadamente as desenvolvidas para medir o quociente de inteligência (QI) e suas conhecidas justificativas para as diferenças sociais entre os indivíduos.

Para apreender as linhas de forças sociais que atravessam esse processo, agregue-se que a defesa de uma escola inclusiva é apontada por Afonso (1999, p. 59) como palco de tensões, ao salientar que historicamente ela integrou projetos sociais antagônicos, quer por parte daqueles que a enfeixam na lógica de mercado, quer por parte daqueles que a veem como um espaço de desenvolvimento de direitos. Direitos que parecem negados quando se verifica que perto de $25 \%$ dos alunos do ensino fundamental não são promovidos à série seguinte.

Nesse quadro, Perrenoud (1999, p. 165) situa o desafio democrático ao sustentar que:

\footnotetext{
O importante, na democratização do ensino, não é "fazer como se" cada um houvesse aprendido, mas permitir a cada um aprender. Quando não se consegue isso, a solução não é esconder a cabeça na areia, mas reconhecer um fracasso, que é, primeiramente, o da escola, para melhor "retomar o trabalho”. Aí está a verdadeira clivagem: frente a desigualdades
}

de aquisição e de níveis escolares devidamente constatados, uns baixam os braços e invocam a fatalidade e os limites da natureza humana, outros buscam novas estratégias.

Estratégias que, sem ignorar as forças que conformam a sociedade, favoreçam práticas pedagógicas que superem o direito de acesso à escola e comprometamse com que todos os alunos tenham o máximo de aproveitamento, tensionando o credo liberal de que todos têm o direito de almejar o sucesso, mas não de consegui-lo.

\section{Os ciclos e o tensionamento da seriação}

Tomando-se trabalhos como os de Vidal e Faria Filho (2005), Souza (1998) e Tyack e Tobin (1994), tem-se a escola seriada como modelo hegemônico e, ao mesmo tempo, com a aparência de único, como forma de organizar a escola de massas e seletiva. Diante desse modelo, ainda a merecer estudos, a organização do ensino em ciclos vem sendo forjada, com ritmos e traços diferenciados, mesmo que mais potencial do que efetiva.

Sem um modelo, os ciclos instauraram, ao menos, tensão na escola seriada, propugnando uma escola obrigatória na qual todo e qualquer aluno pudesse se aproveitar plenamente de seu currículo. Com os ciclos, introduziu-se, com diferenciações, uma polarização com a ideia imanente à seriação, de que ao final de cada ano letivo a avaliação seja sinônimo de aprovação ou reprovação de cada aluno, relevando-se a noção de que o transcurso da escolarização não seja condicionado por ameaças ou reprovações, mas que seja "automático", fluido ou ainda "continuado", na perspectiva da igualdade de resultados.

Ademais, no debate sobre a organização do currículo em ciclos, não se justifica epistemológica, cognitiva, social, econômica, moral, política e, sobretudo, pedagogicamente que tal fluxo escolar seja condicionado por tais avaliações, não podendo concluir que não sejam necessárias as atividades avaliativas, como em Sousa e Alavarse (2003), que demarcaram a centralidade da avaliação no contexto dos ciclos. 
Sustenta-se, portanto, a possibilidade de transformar a escola num centro promotor de aprendizagem sem "terminalidade" profissional, tampouco com destinos sociais traçados - ou definidos formal e abertamente - por essa instituição, ainda que implicitamente isso não possa ser eliminado por uma proposta escolar, por conta das fortes pressões sociais nesse sentido, cuja reversão transcende às possibilidades da própria escola.

Defender tal escola é assumir uma posição política que enseja destacar seu lugar social como aquele que permitiria a democratização do saber para todos os seus alunos pela apropriação organizada e sistemática do conhecimento acumulado pela humanidade mediante o uso da razão, como em Burke (2003, p. 183), e pela geração de novos conhecimentos ante novos e velhos problemas, ainda que os usos ulteriores à escolarização básica desses conhecimentos também possam ser objeto de disputas político-econômicas sobre as quais a escola não tem controle, ainda que possa problematizá-las.

Para tanto, os professores, com liberdade e responsabilidade, teriam pela frente aquilo que Vygotsky (2001, p. 457-459) considerou a "pedagogia sob o aspecto de luta”, isto é, o confronto com os obstáculos que os alunos possam evidenciar por estarem numa sociedade que não advoga consensualmente esse tipo de relação com o conhecimento. Particularmente, um desdobramento é a tentativa de superar práticas avaliativas somativas que reforçam a noção utilitarista do conhecimento ao atribuir às notas escolares um valor de troca associado a um valor de uso, distante muitas vezes do conhecimento, pois expressaria sucesso na carreira interna à escola - aprovação - e promessas de ascensão social. Esse quadro, em boa medida, explicaria a ausência de constrangimento em obter boas notas por meios facilitadores ou até "ilícitos".

A polarização entre ciclos e séries ganha relevância se estiver acoplada à discussão dos procedimentos mais convenientes para o incremento do aproveitamento escolar, pois, se série significar a defesa da reprovação como ameaça capaz de levar alunos a aprender ou ciclos significar apenas o seu adiamento, a polarização estará esvaziada de seu conteúdo político de efetiva democratização da escola.

Embora possa ser considerado um avanço, a eliminação apenas ou o adiamento da reprovação (um dos traços mais avultados da escola seriada) pode manter a concepção - ensinada aos alunos - de que a escola básica não é necessariamente para todos, ou, sendo de todos, não é igualmente aproveitada por todos, repondo a seletividade. Essa concepção, altamente incidente entre os professores, tem como argumento que a vida "fora da escola" seleciona e, portanto, os alunos precisam aprender a enfrentá-la. Politicamente, esse é um argumento forte e procedente pelo respaldo empírico da visão meritocrática ou inatista sobre os melhores predestinados ao sucesso e merece ser confrontado por conter um posicionamento sobre os objetivos e fins da escola.

Para a defesa da escola em ciclos, tal argumento pode ser contestado politicamente pelo reverso empírico, ou seja, na vida “fora da escola” há outras práticas, na perspectiva de uma sociedade que rompa com a seletividade - em seu sentido de desigualdade social - e se apoie no desafio de enfrentar coletivamente as grandes necessidades sociais. A escolha da forma de organizar a escola, não sendo "natural”, deve estar associada à questão do para quê escola? e implica um posicionamento que, a começar dos gestores, pela posição política que ocupam, deve explicitar e, ao fazê-lo, com ou sem consenso, fortaleceria a educação política dos atores e usuários da escola.

Não há solução no equacionamento dos ciclos que contorne o problema político da democratização da escola - entendida como o tensionamento de seu sentido liberal -, isto é, a igualdade de oportunidades transformada na possibilidade de que todos tenham o máximo aproveitamento da escola. Isso não representa a defesa de que a escola possa reverter relações sociais que limitam sua democratização. Trata-se de politizar as soluções organizativas da escola e levar ao extremo suas possibilidades. Tensionar o liberalismo não significa automaticamente superá-lo, mas revelá-lo com suas contradições sociais.

Por isso, nas propostas de ciclos apresentadas em favor da democratização da escola, é preciso localizar 
quais são os passos para transformações curriculares efetivas, pois pode haver mudanças apenas nominalistas, apenas intenções de romper com as consequências negativas da seletividade, sem apontar nem viabilizar medidas decisivas para a alteração da escola.

Ainda que se considere que a escola não seja panaceia nem instrumento absoluto para a superação de problemas sociais, sua construção histórica consubstancia-se como disputa social, pois, conforme Petitat (1994), como instituição social produz e reproduz a sociedade, ainda que cada conjuntura histórica possa favorecer uma ou outra perspectiva. De toda maneira, a escola inscreve-se no movimento histórico e social com as classes sociais, suas frações ou mesmo vários grupos de interesse, movimentando-se com mais ou menos nitidez, explicita ou implicitamente, para projetar nela suas demandas. A escola decorre de forças políticas e culturais relativas, em função de quem a propõe e das condições e correlações de forças em disputa, contestando a visão, fortemente arraigada, que naturaliza sua existência.

Assim, inscrita no plano histórico e político, a organização da escola está sujeita às orientações que emanam das tensões sociais. Por isso, não existe, em absoluto, melhor proposta, mas sim propostas relativas e históricas, o que para Nóvoa (2007) se traduz em dilemas da organização escolar. Tudo isso salienta e legitima que se faça a discussão da organização da escola de uma perspectiva política, sem voluntarismo e sem automatismo.

De passagem, pode-se compreender a dificuldade em apreender esse movimento em decorrência de as políticas educacionais serem apresentadas amiúde, em programas que não as explicitam completamente ou cujos protagonistas não desejam fazê-lo.

Delineando consequências quanto à organização do trabalho pedagógico, Viñao Frago (1990) escreveu que a seriação pode ser admitida pedagogicamente pelo motivo de que genericamente seja a gradação dos objetos de ensino e, portanto, seleção e ordenação de conteúdos, a fim de que se possa melhor ensinar. A escola seriada, por seu turno, seria uma organização que opera para fragmentar os conteúdos, para melhor selecionar e ordenar os alunos. Historicamente, o atendimento de amplas camadas sociais, quer por necessidades daqueles que viam nisso um mecanismo de controle social, como fundamentou Talcott Parsons (1959), quer por pressões vindas “de baixo” para ampliação de direitos, mas em algum grau marcado pelo clima liberal de igualdade de oportunidades, acabou por consagrar a escola seriada e suas condizentes práticas avaliativas somativas.

Em outro trabalho, Viñao Frago (2004, p. 136137), tendo em conta as características dos sistemas educativos formais, destaca que a estruturação vertical do ensino primário em séries e etapas mediante a introdução e difusão de exames, provas e decisões de promoção de série, decorreu ao longo do século XX articulando a extensão da educação obrigatória com a escola graduada, gerando adicionalmente o fenômeno do fracasso escolar e dos repetentes.

Nesse contexto de fragmentação da organização escolar, até a docência foi paulatinamente se especializando, resultado da manufatura que aí foi se alojando com suas consequências para esse tipo de trabalho, produzindo um profissional que, nos marcos da divisão social do trabalho, se identifica como aquele que seleciona pelo saber que domina. Isso explicaria, pelo menos em parte, a chamada resistência docente às medidas que diluam a autoridade selecionadora materializada nas práticas avaliativas.

Essa situação nos remete para impasses da democratização da escola, salientados, entre outros, por Freitas (2004, p. 10) ao caracterizar as finalidades correntes da escola atual como situadas não na inclusão e no conhecimento para todos, mas em conhecimentos mínimos para todos e seleção dos mais competentes, ponderando ainda que as iniciativas de ciclos de progressão continuada, particularmente as da rede estadual paulista, não fogem a essa regra.

Porém, se tal afirmação de Freitas é bastante verossímil, no quadro de outras iniciativas de ciclos ela não deve levar, em primeiro lugar, a procurar exclusivamente na escola a superação desse impasse, dado que é resultante de condições impostas pelas relações sociais em vigor. Recordemos que, mesmo 
em situações de ausência de escola, o recrutamento para postos da hierarquia social se fez presente. Historicamente, aqui e alhures, ocorreu que a instituição escolar mostrou-se eficaz para tarefas de seleção, ainda que não a tenha criado. A possibilidade de estabelecermos pela ação da escola um tensionamento nessa ordem de coisas não pode nos conduzir à crença de sua superação por via dessa instituição.

Em segundo lugar, mais em concordância com Freitas, se a adoção de ciclos em várias redes e em escala bastante avantajada não levou à ruína da escola, também não representou alcance de patamares há mais de duas décadas prognosticados, mesmo naquelas escolas de redes, cujos dirigentes justamente sustentavam que a proposta era de inclusão social e cognitiva. Eis, pois, um desafio a ser aprofundado também em pesquisas acadêmicas, carentes de base empírica, como aliás demarcaram Sousa e Barretto (2004). Subsidiariamente, a continuidade de pesquisas desse porte deve considerar, por hipótese, a existência de muitas redes, sobretudo municipais, que adotaram os ciclos e podem estar desencadeando experiências sui generis que ainda não foram objeto de avaliação ou investigação, mas que podem conter contribuições que fariam avançar o debate e o acervo de iniciativas.

Reforça essa demanda empírica tanto as observações de Canário (2006, p. 91), diante da constatação da impossibilidade de alteração absoluta da realidade por decreto - muitas vezes eivadas de insuficiência teórica e autoritarismo prático -, quanto o fato de que nas escolas onde essas alternativas de organização são estabelecidas acaba-se operando uma apropriação da proposta de tal modo que vêm a resultar em algo distinto daquilo que se cogitava no plano da política educacional, como, aliás, pode-se derivar de, entre outros trabalhos, Alavarse (2007), Arcas (2003), Bertagna (2003), Cabrera (2005), Frehse (2001), Gomes (2004), Jeffrey (2006) e Negreiros (2004).

\section{Os ciclos e a superação da repetência}

Seguramente, o tópico da aprovação/reprovação concentra boa parte da polêmica em torno da adoção dos ciclos. Os que defendem a seriação stricto sensu argumentam que, intrinsecamente, ela não impede a aprendizagem de todos, pois no caso da reprovação/ repetência se estaria dando mais tempo - um ano ou quantos mais forem necessários - para que o aluno efetivamente atinja o que se considera indispensável. Poder-se-ía concordar com tal raciocínio ao preço de nos alinharmos a uma concepção errada ou a uma abstração completa.

Uma apreensão mais crítica da história das práticas seletivas evidencia que, como regra, a repetência não é associada a procedimentos pedagógicos confiáveis de "recuperação" ou de incremento cognitivo dos que a experimentam. Portanto, a promessa de sucesso gera não lógica, mas empiricamente - muito mais o fracasso escolar, revelado nos elevados índices de reprovados, com defasagem idade-série e evadidos, sendo que neste último quesito a reprovação é fator indutor.

A estratégia da repetência, ademais, significa o emprego de recursos materiais e humanos de eficácia e eficiência reduzidas, e sua eliminação - a promoção automática, como acusam os oponentes - não é meramente redução, mas otimização de recursos. Contudo, com a defesa dos ciclos, quando se passa da eliminação da reprovação à ampliação dos níveis gerais de aprendizagem, obrigatoriamente se passa para a necessidade da elevação de recursos, agora já otimizados.

Diante das nefastas consequências sociais e pedagógicas da reprovação na escolarização obrigatória, são plenamente defensáveis as políticas públicas que visam impedi-la, como regra. Disso não decorre $a$ fortiori, apesar das construções discursivas que a acompanham com muita frequência, que sua eliminação garanta mecanicamente a escolarização em patamares satisfatórios para os alunos que se livram da reprovação, sendo necessários esforços adicionais para que os alunos possam ter, na escolarização sem repetência, um salto de qualidade em suas aprendizagens.

Verifica-se nas escolas seriadas ou naquelas em ciclos, mas com a possibilidade de reprovação ao final de cada uma deles, que, salvo situações de flagrante injustiça, os alunos que repetem uma série são aqueles 
que no ano anterior apresentavam desempenho que os colocava em posição inferior em relação ou a um determinado padrão mínimo esperado ou à média de sua turma. Porém, dada a dificuldade de se fixar tais padrões e pelo caráter frequente de avaliações por norma - referida ao grupo de alunos de cada professor -, pode-se aventar que tais decisões estejam eivadas de preocupante relatividade.

Considerando a hipótese de que os alunos repetentes são alunos que podem ter tido efetivamente baixo aproveitamento - supondo algum tipo aceitável de critério - no ano anterior e para os quais uma solução pedagógica seria justamente a repetição para melhorar sua aprendizagem, cabem alguns questionamentos. Como nenhum aluno é reprovado exatamente no final da série, pois que as dificuldades que o levaram a essa situação são cumulativas, a reprovação resultaria sobremaneira da ausência de estratégias e dispositivos de ensino que identificassem e superassem, o mais precocemente possível, essas dificuldades.

Nos relatos de investigações que concluíram pela ineficácia da repetência, como em Crahay (2003), há um consenso de que via de regra se oferece ao repetente o mesmo mais uma vez, quer dizer, ele é conduzido a uma série que já cursou e recebe o mesmo ensino que não teria produzido o efeito considerado satisfatório pela escola, e esse aluno é tratado da mesma maneira que os colegas que estão ingressando na série pela primeira vez. Soma-se a isso a aura de seletividade e punição que, em alguns casos, se traduz por um julgamento definitivo cuja sentença é a declaração de que alguns alunos não possuem condições para a aprendizagem escolar, daí que, quando se consagra a evasão desses alunos, não se vê nisso motivo para indignação e busca de explicações e reversão.

Não obstante a hipótese de que alguns alunos possam se beneficiar da repetência, pesquisadores que encontraram tal resultado são unânimes em afirmar que isso ocorreu em escolas com a mobilização de esforços e recursos que não transformaram a repetência simplesmente em um fazer de novo a mesma série, notadamente porque foram efetivados procedimentos que individualizaram - ainda que não absolutamente
- o percurso escolar desses alunos, operando sobre as dificuldades que redundaram na reprovação, não se constatando a repetência como resultado de punição ou justificada pela associação de baixo desempenho acadêmico com predicados morais dos alunos, como por exemplo "vagabundice” ou "preguiça”; tampouco se buscou preterir os menos capazes.

Contudo, para reiterar a contraindicação da repetência há a ressalva de que escolas desse naipe são poucas, raras na verdade, em relação às que adotam a repetência como pedagogia. O que se pondera é que, primeiro, usualmente, essas condições não estão disponíveis nas escolas que adotam a repetência, mesmo naquelas que alegam adotá-la como expediente estritamente pedagógico. Em segundo lugar, havendo a possibilidade de atividades que possam incidir mais individualizadamente para alunos com dificuldades, o mais indicado é que ocorram antes que a situação de reprovação se consubstancie.

Os argumentos até aqui apresentados nos levam a sustentar que a repetência seria fruto de um "abandono” pedagógico ao longo da série já cursada ou, com sua efetivação, seria pouco eficaz para elevar o aproveitamento escolar.

Outro aspecto importante é que a repetência é contraindicada, na imensa maioria dos casos, por não resultar em ganho para os que estão repetindo em relação aos que foram promovidos estando em idênticas condições no ano anterior, ou seja, alunos com dificuldades e promovidos se beneficiam mais da promoção do que seus congêneres reprovados. Seguir com o mesmo grupo permite maiores ganhos do que integrar um novo grupo como repetente.

Então, tudo indica não haver ganhos expressivos na adoção de tal expediente pedagógico - a "pedagogia da repetência" identificada por Ribeiro (1991) -, ou, pior, geralmente são maiores os malefícios, sobretudo por conta das condições materiais precárias que se somam às crenças de seletividade e de punição que cercam os alunos submetidos a tais práticas. Portanto, a alternativa é apontar para uma escolarização não sujeita à hipótese da reprovação e desenvolvida na perspectiva de que todos possam aproveitá-la ao máxi- 
mo, demandando ações pedagógicas de enfrentamento do fracasso escolar, lançando mão de uma pedagogia da promoção.

Outra face dessa problemática é a existência, com frequência, de quem defenda os ciclos “em essência”, mas não "em existência”, alegando que foram implantados sem condições. Mais ou menos veladamente, o encaminhamento seria a volta ou a manutenção da seriação. Contudo, trata-se de uma posição frágil, pois, em primeiro lugar, daria a entender que nas situações "sem condições” bastaria a seriação; em segundo lugar, a defesa de escolas “com condições” é conditio sine qua non para qualquer escola, em qualquer forma de organização. Conforme salientado, a possibilidade de reprovação, favorecida pela seriação por conta dos objetivos e valores que historicamente fizeram-na quase que a forma escolar - por excelência, pela excelência e para a excelência -, não deveria ser advogada diante das depauperadas condições de existência em que os ciclos se estabeleceram; os ciclos em essência e em existência encerram uma visão de escola que confrontam princípios da seriação, de uma escola que se paute pela inclusão de todos, a partir de quaisquer condições.

A seriação, mesmo que não seja causa em si mesma do fracasso escolar, propicia um quadro no qual ele floresce mais vivamente, além de limitar novas perspectivas pedagógicas. Por conseguinte, especialmente no seio do professorado, a tarefa é lançar as bases para uma escola que não selecione, a partir do que se levantam as exigências de condições para seu pleno funcionamento.

Então, como em Gomes (2005, p. 30), se a "reprovação não é remédio e não raro age como veneno", e supondo-se que a "doença” seja o baixo desempenho, qual seria o remédio? Seguramente as noções de cidadania evocadas no cenário de competitividade revestem-se de eufemismo, pois escamoteiam que não se está fixando um horizonte de pleno sucesso para todos, pois, ao contrário, apenas alguns cidadãos vão ganhar. A escola não pode inverter o quadro de tensionamento social e, nesse sentido, não pode ser um "remédio" absoluto, mas pode ser organizada com base em políticas públicas; primeiro, para atenuar em seu interior os mecanismos que, pior do que obstaculizar um pretenso ascenso social, produzam a desmoralização pela crença, imputada explicitamente de incapacidade; depois, pode estabelecer um compromisso pelo ensino e pela aprendizagem que resulte no chamamento aos professores não como culpados potenciais, mas como profissionais que devem responder pelas aprendizagens de seus alunos; $\mathrm{e}$ responder significa estabelecer uma interlocução com os dirigentes, interlocução que pressupõe a possibilidade de divergência e levantamento das causas dos eventuais resultados discrepantes e das condições a serem satisfeitas.

\section{Os ciclos e os objetivos escolares}

A polarização entre ciclos e séries ganha força sem ser a de um divisor mítico de águas - se forem considerados os objetivos do ensino fundamental. A palavra ciclo(s) designa período temporal ou duração de um processo para que algo ocorra; assim, o ensino fundamental constituiria um ciclo, ou poderia ser desdobrado em períodos - ciclos - menores, mas a questão é: quais são os objetivos de tal(is) ciclo(s)? Essa questão traz imbricada uma outra: a duração é indiferente aos objetivos? Considerando-se que a duração do processo tem profundas relações com os resultados almejados, a opção por uma ou outra forma de organização deveria indicar as pretensões do processo pedagógico; ou seja, a recorrência à seriação, tal como ela se estrutura, indica como meta aquilo que seja possível após a duração de um ano letivo menor do que um ano - e agravado pelo risco de não ser atingível por todos.

Ao contrário, a proposição dos ciclos deve conduzir a um alongamento do tempo para que se possa trabalhar com objetivos mais amplos do que aqueles anualizados; portanto, ampliando as finalidades da escola e permitindo que se trabalhe melhor, isto é, que se trabalhe para que todos possam aprender. Por isso, sem forçar denominações artificiais, essas preocupações conduziriam aos ciclos de aprendizagem, por fazer do 
objetivo de aprendizagem um aspecto central, o que não pode ser interpretado como desconsideração pelas condições peculiares dos aprendizes e sua cultura, nem contornar o imenso problema político de quais devem ser os objetivos de aprendizagem, como pode ser apreendido no desafio de delimitação curricular da rede paulistana de 1989 a 1991, destacado no relato de Sampaio, Quadrado e Pimentel (1994).

Ainda no que tange à ideia de ciclos como períodos, há uma proposta de ciclos que se apoia nos grupos conformados por faixas etárias, diferenciadas entre si pela configuração de ciclos de vida que, por seu turno, estabeleceriam objetivos específicos para a escola organizada em função dos ciclos de vida. Essa fundamentação, em termos majoritariamente psicológicos e ainda que reconhecendo as bases culturais do condicionamento de tais ciclos, conduz aos ciclos de formação - ou ciclos de formação humana -, cujos formuladores identificam três grandes agrupamentos etários: infância, pré-adolescência e adolescência, com tratamento pedagógico correspondente.

Além das discrepâncias que as duas grandes experiências de ciclos de formação apresentam - nas redes municipais de Belo Horizonte e Porto Alegre -, encontramos nos aportes de Teixeira (2004) que qualquer periodização que se sustente em teorias psicológicas - mesmo que agreguem dimensões culturais - são bastante arbitrárias e com diferenciações conforme a teoria tida como paradigmática, obrigando a concessões de outras ordens de fatores, administrativos especialmente. O próprio Teixeira, que procurou fundamentação na psicologia histórico-cultural, vê-se obrigado a sugerir três ciclos de aprendizagem, diferentes do modelo que suas hipóteses indicavam - dois ciclos, sendo um de seis anos e outro de três, para um ensino fundamental de nove anos.

Ainda no tocante às limitações de segmentações desse porte, além das ponderações de Arelaro, Telles e Kruppa (1998), podemos nos apoiar em Azanha (1998b) para mencionar o caráter restritivo de procurar enfeixar processos pedagógicos em teorias psicológicas exclusivas, sem, contudo, tirar o mérito do debate sobre tais teorias e seus alcances pedagógicos.
A ideia central, portanto, para a adoção dos ciclos de aprendizagem seria o combate político à exclusão, mas cujo verdadeiro alcance se manifesta na inclusão dos alunos no universo do conhecimento, rompido o esquema seriado que faz o processo pedagógico orbitar sobre o binômio aprovação-reprovação ao final do ano letivo.

Além dos aspectos já elencados, para a viabilização dos ciclos deveria se partir da escola tal como se encontra, ou seja, uma “máquina seletiva” fortemente legitimada para tal objetivo. Trata-se, no fundo, de uma operação de combate e convencimento político, aliada a condições materiais que potencializem a democratização da escola para evidenciar que o modelo mais tradicional de escola nem mesmo garante os melhores conhecimentos para os não muitos que nela triunfam.

Por isso, com todas as limitações das avaliações externas e em larga escala, não podemos descartar os indicadores que emanam da Prova Brasil e do SAEB, entre outras avaliações, que enfraquecem as críticas à promoção automática por considerá-la fator de queda da “qualidade do ensino”. Em Alavarse (2007) encontramse análises de desempenho de redes públicas contrastadas em função da existência de ciclos ou séries, e o que se observa, contra o senso comum pedagógico, é que a ausência de ameaças de reprovação das redes com ciclos não levou a desempenhos inferiores aos das redes com seriação. Contudo, essas avaliações apontam, também, que importantes redes que adotam os ciclos ainda estão por verem cumpridas as promessas de incremento do desempenho. O que, aliás, ainda se configura como um desafio para o conjunto dos alunos brasileiros.

Essas constatações indicam que a polarização entre ciclos e séries pode ser abordada num permanente diálogo com os professores - o principal segmento para levar adiante a proposta - para que a divergência possa ser enfrentada com dados mais objetivos, sem, obviamente, eliminar a dimensão política do debate.

\section{Os ciclos e algumas implicações pedagógicas}

Ressaltada sua implicação política, os ciclos podem ser tomados em seus desdobramentos intraes- 
colares, o que comporta, entre outros fatores, currículo, gestão e relações de trabalho - relações não só entre os profissionais, como também entre estes e os alunos.

A potencialização dos ciclos, além de medidas que dotem as escolas de adequadas condições materiais e profissionais de funcionamento e da consistência teórica das iniciativas de sua implantação com vistas a alterações significativas no processo de escolarização - compreendidos seus fins -, impõe que no locus privilegiado da ação pedagógica - a escola - sejam observadas algumas características. Por isso, pode-se ponderar, inicial e subsidiariamente, que em cada unidade escolar sejam observados os seguintes elementos, com vistas à superação da seriação, envoltos obviamente por um clima de amplo debate:

a) proposta político-pedagógica ancorada no diagnóstico da situação inicial que explicite os objetivos de aprendizagem ao longo de cada ciclo, na perspectiva de uma visão ampla de currículo que transcenda o rol e o encadeamento de conteúdos disciplinares;

b) organização do trabalho pedagógico com destaque para as modalidades de engajamento da equipe de professores, articulando jornadas de trabalho e tarefas no seio de um verdadeiro trabalho coletivo, isto é, um grupo de professores sendo responsável por um grupo de alunos ao longo de cada ciclo;

c) delimitação de formas e expedientes de acompanhamento das aprendizagens dos alunos que contemplem as ações pertinentes à superação de eventuais obstáculos, realçando a avaliação formativa e institucional;

d) estabelecimento de procedimentos de agrupamento dos alunos na perspectiva da diferenciação pedagógica e da individualização de percursos;

e) disponibilização de recursos e arranjos materiais, com a ampliação dos espaços de aprendizagem que, seguramente, extrapolam a sala de aula e a própria escola como ambientes exclusivos de ensino e aprendizagem; f) cotejamento dos indicadores da escola com aqueles do conjunto das escolas nacionais e regionais, a despeito da singularidade cada unidade escolar.

Dos elementos apresentados, pode-se destacar, preliminarmente, o processo de agrupamento dos alunos no sentido de superar as características tradicionais de “enturmação” da escola seriada. Usualmente, como expressão da organização horizontal das séries, as turmas são formadas para existir por um ano, e nesse período, salvo exceções, não sofrem alterações. Como corolário, essa enturmação faz corresponder um professor para cada turma, no segmento dos anos iniciais do ensino fundamental, ou um professor especialista para cada disciplina nos anos finais, com pouca ou nenhuma articulação entre e intra segmentos.

Os agrupamentos devem ser flexíveis e constituídos em função das tarefas pedagógicas, dos critérios - de capacidades, dificuldades ou de interesses de alunos e professores - e articulados com os objetivos de aprendizagem do ciclo. Essa organização de agrupamentos flexíveis de alunos deve ter como contrapartida a organização dos professores de tal modo que um grupo de professores seja responsável por uma coorte ou parte dela, constituída pelos alunos que ali se matriculam em um determinado ano e que deveriam ser acompanhados ao longo de cada ciclo ou até ao longo de todo o ensino fundamental para resultados mais equânimes ao final do percurso.

Isso decorre do desafio e compromisso da escola não apenas com o ensino - o que já seria de grande envergadura -, mas, sobretudo, com a aprendizagem de seus alunos e representaria o que Meirieu (1997), Perraudeau (1999), Perrenoud (2000) e O’Brien e Guiney (2001), entre outros, destacaram como condição para a diferenciação pedagógica, a fim de que todos possam aprender, que deve ser vista como uma iniciativa não apenas para situações nas quais não se obtêm os resultados esperados, mas sim como um estratagema regular de trabalho pedagógico. Um grupo de professores trabalhando com um grupo de alunos pode tanto potencializar a ação pedagógica quanto 
estabelecer um cronograma de trabalho no qual se dê atenção aos vários tipos de necessidades dos alunos mediante a diferenciação do trabalho dos professores.

A diferenciação pedagógica é uma estratégia para superar pelo menos duas outras características marcantes da seriação: simultaneidade e uniformidade. Essa superação é necessária, pois se sabe que ensinar praticamente ao mesmo tempo a mesma coisa para todos os alunos produz, tendencialmente, grande diferenciação de resultados que, por sua vez, é a base do espírito classificatório e seletivo da moderna escola elementar de massas, em sua organização vertical.

A existência e a conformação das turmas da escola seriada devem ser problematizadas pelo fato de que, a rigor, não existem turmas homogêneas, mas turmas com graus de heterogeneidade - mesmo quando se atém ao desempenho cognitivo. Sabe-se ainda que outro efeito correlato, mais denso politicamente, advém do fato de que as turmas cuja "homogeneidade" é serem constituídas por alunos com menor aproveitamento acabam, contraditoriamente, recebendo menos atenção e esforços de trabalho pedagógico e, às vezes, são "empurradas" a um professor que ficou em último lugar na escolha de turmas ou que recém-ingressou na escola. E nessas turmas as diferenças entre os alunos tendem, no mínimo, a se manter, mantendo também a diferença em relação a outras turmas e consolidando um processo de exclusão ou restrição no acesso ao conhecimento que se agrava com o passar do tempo. Portanto, o problema não está em considerar que os alunos tenham diferenças, mas em como tratar essas diferenças, o que se converte num desafio democrático de equidade. A diferenciação pedagógica prescinde da ideia de reprovação ao desencadear ações que evitam o acúmulo de dificuldades em cada aluno, o que tem justificado a reprovação e a repetência.

Adicionalmente, as tentativas de individualização de percursos de escolarização devem significar uma preocupação com cada aluno sem que, necessária e exclusivamente, isso conduza ao ensino individualizado, até porque isso exigiria uma reconfiguração material e política da escola que está fora de cogitação neste momento. A combinação, ao longo do ciclo, da diferenciação pedagógica com a individualização de percurso - que não significa ensino preceptoral nos dizeres de Azanha (1998a) - seria uma resposta da escola para eliminar ou atenuar acentuadamente as diferenças de resultados que o processo de composição de turmas facilita.

Verifica-se, especialmente nas escolas seriadas, que o acompanhamento dos alunos muito frequentemente se reduz a uma troca de informações superficiais ou imprecisas, esporadicamente ao longo do período letivo, que não resultam em ações mais incisivas dos professores. Por conta disso, e também em relação com o tipo de objetivo a ser atingido, a duração de um ciclo deve, portanto, ser superior ao tradicional ano letivo para se dispor de mais tempo de trabalho com os alunos. Isso configuraria, estatisticamente, um movimento na escola no qual a média de aproveitamento dos alunos se encaminha para o máximo e o desvio-padrão, para o mínimo.

Se os expedientes de reforço e recuperação constituem-se em iniciativas de diferenciação pedagógica, todavia, nas condições materiais em que usualmente ocorrem, sua eficácia é muito baixa, sobretudo porque não há o mais importante: a conjugação do trabalho coletivo entre os professores regulares das turmas e os professores que desencadeiam as tarefas de reforço e recuperação. Há também nesses moldes de reforço e recuperação um aspecto negativo, que é a estigmatização dos que delas se servem - isso quando não há a condenação dos indisciplinados aos "trabalhos forçados” nas salas de reforço. Mas, principalmente, sua existência não abala nem questiona a principal maneira de agrupamento, que é a conformação das turmas.

Ainda com respeito às turmas e para enfatizar suas consequências, as avaliações externas, inclusive fora do Brasil, têm confirmado que as diferenças de médias entre as turmas de uma escola são maiores que a diferença entre as médias das escolas, chamando a atenção para os fatores internos às escolas que favorecem essa situação e permitindo, ainda, especular que a diferença entre as turmas possa ser produto da enturmação por critérios que discriminam turmas 
“fortes” e "fracas" e obstaculizam a reversão tanto das dificuldades dos alunos, quanto da própria hierarquização entre as turmas.

Esses aspectos reiteram a necessidade de investir em novos paradigmas de trabalho docente e agrupamento de alunos, inclusive para que se evite o isolamento docente e para que a maior capacidade de trabalho de alguns docentes seja posta a serviço do conjunto dos alunos e até dos outros professores. Nesses termos, a clássica reivindicação dos professores pela diminuição do número de alunos por turma - justa nos marcos em que surge, mas limitada a estes - ganharia novo contorno, de um novo trabalho docente.

Assim, a concepção de trabalho com a coorte de ingresso, exposta anteriormente, pode avançar para um verdadeiro trabalho coletivo e forçar o desaparecimento da atribuição de turmas hierarquizadas aos professores - que às vezes ocorre como prêmio ou castigo -, em favor de uma postura que reconhece potencialmente a diversidade inicial dos alunos e tenta estruturar uma alternativa para que isso não se transforme no berço de diferenças ulteriores.

\section{Os ciclos e alguns obstáculos}

A partir do contato direto e de relatos sobre a realidade de muitas escolas consideradas organizadas em ciclos, pode-se dizer que a polarização com o modelo seriado é muito mais retórica do que empírica. Mesmo diante das principais iniciativas de implantação de ciclos no Brasil - localizadas nas redes públicas de Belo Horizonte, Porto Alegre e São Paulo (estado e município) - não seria possível apresentar um paradigma de ciclos, mas alguns elementos que compõem um quadro ainda muito inicial de alternativas à seriação. Essas redes, contudo, se comparadas ao conjunto das redes públicas que são esmagadoramente seriadas e excludentes, indicam avanços significativos, mesmo que se considere que estão longe dos objetivos preconizados por seus idealizadores.

A tradição seriada não valorizou a necessidade de esforços de atendimento aos alunos - mesmo no curto período anual - para que todos tivessem sucesso, notadamente porque a seletividade que lhe é imanente nunca exigiu; antes, a seletividade é facilitada pela diferenciação entre os alunos. Todavia, os ciclos podem estar significando um período mais longo que o tradicional ano letivo durante o qual não estejam sendo mobilizadas, efetivamente, estratégias e condições para um nítido contraste com a seriação e, principalmente, para alavancar as aprendizagens. Como resultado, com uma ou outra forma, não se estaria garantindo que todos aprendam.

Destarte, os dirigentes educacionais que implementam os ciclos não podem ignorar - sob pena de prejuízos para os alunos com dificuldades escolares-, principalmente quando a duração dos ciclos excede em muito a um ano, que ciclos podem estar resultando em alunos "abandonados” dentro da escola; escola na qual, não raras vezes, aliado às limitações materiais, não foi instalado o verdadeiro debate, pois seus profissionais apenas cumprem "ordens superiores". A situação só não é mais nociva porque a prática de reprovação - na qual creem muitos professores - também não agrega substancialmente muita coisa para os repetentes, o que, em si mesmo, não deve ser motivo de júbilo para os que defendem os ciclos, pois períodos mais longos, para se constituírem em alternativa efetiva, devem ser acompanhados de um trabalho diversificado; do contrário, podem ser inócuos, como destacam, a partir da realidade dos Estados Unidos da América do Norte, Alexander, Entwistle e Kabbani (2000) e McMurrer (2006).

Também Mainardes (2001, p. 51) adverte que:

\begin{abstract}
Sem o esforço conjunto dos gestores do sistema educacional, das unidades escolares, dos educadores e demais profissionais envolvidos, vinculado aos esclarecimentos feitos aos pais e alunos, mudanças tão radicais como a organização em ciclos poderão fragilizar, ainda mais, a estrutura e o funcionamento das escolas, causando prejuízos muito sérios aos processos de aprendizagem e constituição de sujeitos.
\end{abstract}

Em contrapartida, se os ciclos também demandam uma revisão dos programas de ensino que estabeleça outros marcos curriculares, pode ser irresponsabilida- 
de política atribuir aos profissionais da escola, isoladamente, a tarefa de forjar um novo modelo curricular que transcenda às clássicas divisões disciplinares. Tal transcendência, além de não ser consensual, nem mesmo entre os acadêmicos que a investigam, apresenta-se como uma tarefa para a qual os professores não foram formados - dado inclusive o caráter extremamente disciplinar dos cursos de formação de professores -, agravado pelo tipo de jornada de trabalho que a imensa maioria dos professores possui nas escolas - nas "cicladas", inclusive.

Tem-se como dificuldade adicional à implantação dos ciclos, quer por concepção, quer por empiria, a resistência a eles pelo fato de terem sido estabelecidos sem levar em conta o direito - legítimo - de divergência e o fato de que as condições de operação das escolas vigentes antes de sua implantação não foram substancialmente alteradas, particularmente as jornadas de trabalho docente.

A trama discursiva em favor dos ciclos tem destacado que a seriação favorece a seletividade operada pela escola, tanto pela fragmentação exacerbada do currículo quanto pelas práticas avaliativas somativas e pela base temporal limitada, quer para que os alunos tenham mais tempo para aprendizagem, quer por restringir o desenvolvimento de objetos de ensino que demandam mais tempo. Em outras palavras, a seriação revela-se um obstáculo à escolarização que se comprometa com a igualdade de resultados.

Entretanto, pode-se encontrar propostas de ciclos que, além de não incrementar as condições materiais das escolas em sua implantação, se apoiam em concepções limitadas ou restritivas dos próprios ciclos. Com efeito, observa-se em muitas redes que a implantação dos ciclos não se fez acompanhar do salto qualitativo prometido, inclusive no domínio da escrita pelos alunos, como mostrou Franco (2004) ao destacar que as escolas em ciclos, se não excluem os alunos da escola, não os incluem no tocante ao letramento, sublinhando-se o caráter instrumental e político da escrita para a apropriação de um amplo conjunto de saberes escolares e condição de acesso aos produtos culturais que dela lançam mão, o que exige a aprendi- zagem não espontânea, como bem ponderou Williams (2000, p. 93), denominando-a democratização da cultura comum pelo domínio da escrita.

Há que se considerar, ainda, as alterações entre a formulação e a implantação dos ciclos, que indicam dificuldades em superar o modelo seriado ou as próprias condições de implantação, como apontam Sousa e Barretto (2004, p. 68-69), pois,

\begin{abstract}
[...] como a concepção dos ciclos não se define tão somente pelos grandes contornos que certas políticas lhes conferem, e como as gestões mudam e as escolas ficam, certamente o significado dos ciclos tem também muito a ver com o sentido que lhe atribuem os próprios atores educacionais que neles têm colocado a esperança de uma escola melhor para todos, ou que os encaram com desconfiança e descrédito ou, ainda, que incorporam apenas alguns traços do novo às suas velhas práticas escolares.
\end{abstract}

Indica-se, desse modo, a necessidade de pesquisas que permitam o levantamento e tratamento de dados sobre a realidade dos ciclos, seguindo pistas como a de Fernandes (2004), que podem render análises que deem conta mais acuradamente dos resultados de sua implementação. Inclusive porque as iniciativas de políticas públicas para redes escolares, com o envolvimento de profissionais, alunos e pais, são de grande complexidade e tensas do ponto de vista das relações com a democratização da escola, pelo eventual choque de interesses.

\section{Os ciclos e algumas indicações}

Apesar de que neste artigo tenham sido alinhavados argumentos mais gerais, sem se debruçar sobre situações concretas, pode-se sustentar em sua conclusão que a adoção dos ciclos não ensejou ainda um quadro educacional que tenha produzido indicadores que sinalizem um salto qualitativo na democratização do ensino fundamental, conforme Alavarse (2007). Com preocupações semelhantes, Mainardes (2004, p. 179) alerta que, até o momento, os ciclos mais potencializam do que efetivam. 
O discurso político da escolarização em ciclos no Brasil é usualmente associado com ideias progressistas tais como democratização, inclusão e melhoria da qualidade da educação nas escolas públicas. [...] A despeito disso [...] desigualdades e exclusões são reproduzidas em tais políticas de ciclos.

A luta em defesa de uma escola onde todos aprendam - expressa em políticas que materializem esse compromisso - choca-se contra a perspectiva do triunfo de poucos, tanto pelo fato de que, ao aprenderem, podem dar-se conta de falácias meritocráticas quanto, igualmente, podem descortinar o alto grau de arbitrariedade contido na seletividade "cognitiva” ou naquilo que Crahay (2003) denominou "ideologia da excelência” que faz com que fracassos escolares não sejam - contra o que amiúde profissionais da educação propalam - reflexo direto do rendimento dos alunos.

Se para Canário (2002) a escola, como instituição social, encontra-se cerceada pelo elitismo e não seria possível concebê-la como motor de transformação social, isso não impede que se lute por sua democratização. Se a democratização da escola alimenta-se da crença, disseminada socialmente, de ser um mecanismo de ascensão social em função do sucesso escolar, podese combater a ilusão no terreno das ilusões defendendo a escola como espaço de aprendizagens - de sucesso - para todos. Aprendizagens que dificilmente serão únicas e tampouco as últimas, pois que na história os objetivos escolares, objetos de disputas sociais, sempre se renovarão, ainda que não completamente, pois enquanto novos se imporão aos velhos objetivos, alguns resistirão e outros perderão sua validade.

Se, socialmente, o efetivo triunfo de todos é algo que extrapola as tarefas da escola, o que se pode constatar é que o projeto educacional consubstanciado na escola seriada não deu conta e não favoreceu sua democratização, por conta dos compromissos políticos e sociais que encerra e que não podem ser completamente explicitados ao preço de revelá-los. Dessa perspectiva, a escola está em questão.

De outro lado, isso exige que se tome a escola como questão, isto é, que seja pensada em sua totalidade; a proposta de ciclos pode contribuir para tanto, pois fica patente o enorme potencial democrático que contempla, mas as evidências de sua implantação revelam que ainda falta muito a ser cumprido.

\section{Referências bibliográficas}

AFONSO, Almerindo Janela. Educação básica, democracia e cidadania: dilemas e polêmicas. Porto: Afrontamento, 1999. (Colecção Polígono, 5.)

ALAVARSE, Ocimar Munhoz. Ciclos ou séries?: a democratização do ensino em questão. 2007. Tese (Doutorado em Educação) - Faculdade de Educação, Universidade de São Paulo, São Paulo, 2007. ALEXANDER, Karl L.; ENTWISTLE, Doris R.; KABBANI, Nader. Grade retention, social promotion and "third way" alternatives. The CEIC Review, v. 9, n. 3, p. 18-19, jun. 2000. Disponível em: <http://www.temple.edu/LSS/pdf/ceicreviews/CEICVol9No3. pdf>. Acesso em: 10 out. 2006.

ARCAS, Paulo Henrique. Avaliação da aprendizagem no regime de progressão continuada: o que dizem os alunos. 2003. Dissertação (Mestrado em Educação) - Faculdade de Educação, Universidade de São Paulo, São Paulo, 2003.

ARELARO, Lisete Regina Gomes; TELLES, Silvia; KRUPPA, Sonia Maria. A organização do ensino em ciclos. São Paulo: s.ed., 1998. Mimeografado.

AZANHA, José Mário Pires. Proposta pedagógica e autonomia da escola. Cadernos de História e Filosofia da Educação, São Paulo, v. II, n. 4, p. 11-21, 1998a.

. Parâmetros curriculares nacionais e autonomia da escola. São Paulo: s.ed., 1998b. Mimeografado.

BERTAGNA, Regiane Helena. Progressão continuada: limites e possibilidades. 2003. 480 p. Tese (Doutorado em Educação) Faculdade de Educação, Universidade Estadual de Campinas, Campinas, 2003.

BURKE, Peter. Uma história social do conhecimento: de Gutenberg a Diderot. Trad. Plínio Dentzien. Rio de Janeiro: Jorge Zahar, 2003. CABRERA, Renata Cristina. A avaliação da aprendizagem no discurso das professoras da escola ciclada de Mato Grosso: um estudo de caso. 2005. Dissertação (Mestrado em Educação) - Programa de Pós-Graduação em Educação, Universidade Federal do Mato Grosso, Cuiabá, 2005.

CANÁRIO, Rui. Escola: crise ou mutação? In: PROST, Antoine et al. Espaços de educação, tempos de formação. Lisboa: Fundação Calouste Gulbenkian, 2002. p. 141-151. 
. A escola tem futuro?: das promessas às incertezas.

Porto Alegre: Artmed, 2006.

CANFORA, Luciano. A democracia: história de uma ideologia. Trad. José Jacinto Correia Serra. Lisboa: Edições 70, 2007. (1. ed. 2004.)

CRAHAY, Marcel. Poderá a escola ser justa e eficaz?: da igualdade das oportunidades à igualdade dos conhecimentos. Trad. Vasco Farinha. Lisboa: Instituto Piaget, 2002. (Horizontes Pedagógicos, 92. 1. ed. 2000.)

Peut-on lutter contre l'échec scolaire? 2. ed. Bruxelles: De Boeck \& Lacier, 2003. (Pédagogies en Développement.) CURY, Carlos Roberto Jamil. Direito à educação: direito à igualdade, direito à diferença. Cadernos de Pesquisa, São Paulo, n. 116, p. 245-262, jul. 2002.

FERNANDES, Claudia de Oliveira. Escola em ciclos: particularidades evidenciadas a partir dos dados do Saeb. Estudos em Avaliação Educacional, São Paulo, v. 15, n. 30, p. 83-105, jul./dez. 2004. FRANCO, Creso. Ciclos e letramento na fase inicial do ensino fundamental. Revista Brasileira de Educação, São Paulo, n. 25, p. 30-38, jan./abr. 2004.

FREHSE, Eike. Democratização em xeque?: vicissitudes da progressão continuada no ensino paulista em 1999. 2001. Dissertação (Mestrado em Educação) - Faculdade de Educação, Universidade de São Paulo, São Paulo, 2001.

FREITAS, Luiz Carlos de. Ciclos ou séries: o que muda quando se altera a forma de organizar os tempos-espaços da escola? In: REUNIÃO ANUAL DA ANPED, 27., 2004, Caxambu. Anais... Caxambu: ANPEd, 2004.

GOMES, Alessandra. Democratização do ensino em questão: a relevância política do fim da reprovação escolar. 2004. Dissertação (Mestrado em Educação) - Faculdade de Educação, Universidade de São Paulo, São Paulo, 2004.

GOMES, Candido Alberto. Desseriação escolar: alternativa para o sucesso? Ensaio: Avaliação de Políticas Públicas em Educação, Rio de Janeiro, v. 13, n. 46, p. 11-38, jan./mar. 2005.

GOULD, Stephen Jay. A falsa medida do homem. 2. ed. Trad. Valter Lellis Siqueira. São Paulo: Martins Fontes, 1999. (1. ed. 1981.)

JEFFREY, Debora Cristina. Representações de docentes sobre o regime de progressão continuada: dilema e possibilidades. 2006. Tese (Doutorado em Educação) - Faculdade de Educação, Universidade de São Paulo, São Paulo, 2006.

MAINARDES, Jefferson. A organização da escolaridade em ciclos: ainda um desafio para os sistemas de ensino. In: FRANCO, Creso
(Org.). Avaliação, ciclos e promoção na educação. Porto Alegre: Artmed, 2001. p. 35-54.

MAINARDES, Jefferson. Moving away from a graded system: a policy analysis of the Cycles of Learning Project (Brazil). 2004. 235 f. Thesis (Doctor of Philosophy) - Institute of Education, University of London, London, 2004.

MCMURRER, Jennifer R. Revisiting retention: issues and alternatives. Arlington: Educational Research Service, 2006. (The Informed Educator Series.)

MEIRIEU, Philippe. La escuela, modo de empleo: de los “métodos activos” a la pedagogía diferenciada. Trad. José María Cuenca Flores. Barcelona: Octaedro, 1997. (Recursos, 17. 1. ed. 1990.) NEGREIROS, Paulo Roberto Vidal de. A seriação enquanto organização dos tempos escolares na rede privada de ensino de Belo Horizonte. 2004. Dissertação (Mestrado em Educação) - Pontifícia Universidade Católica de Minas Gerais, Belo Horizonte, 2004.

NÓVOA, António. Desafios do trabalho do professor no mundo contemporâneo. Edição de palestra proferida em out. 2006. São Paulo: SINPRO-SP, jan. 2007.

O'BRIEN, Tim; GUINEY, Dennis. Differentiation in teaching and learning: principles and practice. London: Continuum, 2001. PARSONS, Talcott. The school class as a social system: some of its functions in american society. Harvard Educational Review, v. 29, n. 4, p. 297-318, fall 1959.

PERRAUDEAU, Michel. Les cycles et la différenciation pédagogique. Paris: Armand Colin, 1999. (Formation des Enseignants - Enseigner.) PERRENOUD, Philippe. Avaliação: da excelência à regulação das aprendizagens: entre duas lógicas. Trad. Patrícia Chittoni Ramos. Porto Alegre: Artes Médicas Sul, 1999.

. Pedagogia diferenciada: das intenções à ação. Trad.

Patrícia Chittoni Ramos. Porto Alegre: Artes Médicas Sul, 2000. PETITAT, André. Produção da escola / produção da sociedade: análise sócio-histórica de alguns momentos decisivos da evolução escolar no ocidente. Trad. Eunice Gruman. Porto Alegre: Artes Médicas, 1994. (1. ed. 1982.)

RIBEIRO, Sergio Costa. A pedagogia da repetência. Estudos em Avaliação Educacional, São Paulo, n. 4, p. 73-85, jul./dez. 1991. SAMPAIO, Maria das Mercês Ferreira; QUADRADO, Alice Davanço; PIMENTEL, Zita Porto. Interdisciplinaridade no município de São Paulo. Brasília: INEP, 1994. (Série Inovações Educacionais, v. 3.) SOUSA, Sandra Maria Zákia Lian; ALAVARSE, Ocimar Munhoz. A avaliação nos ciclos: a centralidade da avaliação. In: FREITAS, Luiz Carlos de; GATTI, Bernadete A.; SOUSA, Sandra Maria Zákia 
Lian (Orgs.). Questões de avaliação educacional. Campinas: Komedi, 2003. p. 71-96. (Série Avaliação: Construindo o Campo e a Crítica.) SOUSA, Sandra Maria Zákia Lian; BARRETTO, Elba Siqueira de Sá (Coords.). Estado do Conhecimento - Ciclos de progressão escolar (1990-2002): relatório final. São Paulo: FEUSP, out. 2004. SOUZA, Rosa Fátima de. Templos de civilização: a implantação da escola primária graduada no Estado de São Paulo (1890-1910). São Paulo: Editora da UNESP, 1998. (Prismas.)

TEIXEIRA, Edival S. A psicologia histórico-cultural como fundamento para a organização do ensino em ciclos de aprendizagem. 2004. Tese (Doutorado em Educação) - Faculdade de Educação, Universidade de São Paulo, São Paulo, 2004.

TYACK, David; TOBIN, William. The "grammar" of schooling: why has it been so hard to change? American Educational Research Journal, v. 31, n. 3, p. 453-479, fall 1994.

VIDAL, Diana Gonçalves; FARIA FILHO, Luciano Mendes de (Orgs.). As lentes da história: estudos de história e historiografia da educação no Brasil. Campinas: Autores Associados, 2005. (Coleção Memória da Educação.)

VYGOTSKY, Lev Semenovich. Psicologia pedagógica. Trad. Paulo Bezerra. São Paulo: Martins Fontes, 2001. (Psicologia e pedagogia. 1. ed. 1926.)

VIÑAO FRAGO, Antonio. Innovación pedagógica y racionalidad científica: la escuela graduada pública en España (1898-1936). Madrid: Akal, 1990. (Akal Universitaria. Serie Sociología, 138.) . Escuela para todos: educación y modernidad en la España del siglo XX. Madrid: Marcial Pons, 2004.

WILLIAMS, Raymond. Cultura. 2. ed. Trad. Lólio Lourenço de Oliveira. Rio de Janeiro: Paz e Terra, 2000. (1. ed. 1981.)
OCIMAR MUNHOZ ALAVARSE, doutor em educação pela Faculdade de Educação da Universidade de São Paulo (USP), é professor do Departamento de Administração Escolar e Economia da Educação na mesma instituição. De 1995 a 2007 foi coordenador pedagógico na Rede Municipal de Ensino de São Paulo, na qual exerceu também o cargo de coordenador do Núcleo de Avaliação Educacional, responsável pela Prova São Paulo - sistema de avaliação externa da rede paulistana. Publicou recentemente: “Ciclos ou séries: a organização curricular em questão” (In: CARVALHO, Gislene Teresinha Rocha Delgado de; UTUARI, Solange dos Santos (Orgs.). Formação de professores e estágios supervisionados: algumas veredas. São Paulo: Andross, 2007. p. 49-69); em coautoria com Sandra Zákia Sousa: “A avaliação nos ciclos: a centralidade da avaliação” (In: PALMA FILHO, João Cardoso; LEITE, Yoshie Ussami Ferrari; ARENA, Dagoberto Buim (Orgs.). Pedagogia cidadã: cadernos de formação: gestão curricular e avaliação. 2. ed. rev. e ampl. São Paulo: UNESP, Pró-Reitoria de Graduação, 2007. p. 101-120); em coautoria com Sandra Zákia Sousa, Paulo Henrique Arcas e Andréa Steinvascher: "Progressão escolar e ciclos: fundamentos e implantação” (In: KRUG, Andréa Rosana Fetzner (Org.). Ciclos em revista: a construção de uma outra escola possível. Rio de Janeiro: Wak, 2007. p. 31-51). Pesquisa atual: “A organização do ensino fundamental em ciclos: conceitos, iniciativas e resultados na perspectiva da democratização da escola”.E-mail: ocimar@usp.br

Recebido em novembro de 2008 Aprovado em dezembro de 2008 